\title{
Prevalence of respiratory symptoms and lung function evaluation in local foundry workers in Kano State, Nigeria
}

\author{
DOI: https://doi.org/10.5114/pq.2020.95773
}

\author{
Aishat Shittu, Abba Abdu Yalwa, Jibril Mohammed
}

Bayero University, Kano, Nigeria

\section{Abstract}

Introduction. Aluminium foundry for kitchen utensils production is a major employer in Kano State, Nigeria. We hypothesized that significant occupational hazard such as presence of respiratory symptoms and impairment in lung function might be prevalent among the workers. The study assessed respiratory symptoms and lung function in foundry workers.

Methods. The cross-sectional survey involved 83 male foundry workers and applied the convenience sampling method. Respiratory symptoms were evaluated with the American Thoracic Society (ATS-DLD-78) questionnaire. Lung function was assessed by using an MSO4 spirometer. The data obtained were summarized by descriptive statistics. Spearman rank order correlation and chi-square were determined between the variables of interest $(p<0.05)$.

Results. The participants' mean age was $24.8 \pm 6.7$ years, with $10-19$ years of exposure in the majority $(43 ; 51.8 \%)$. The prevalence of respiratory symptoms was as follows: phlegm: $69.9 \%$, cough: $33.7 \%$, chest pain: $27.7 \%$, wheeze: $16.9 \%$, haemoptysis: 4.8\%. Lung function (FVC: 0.000 ; FEV1: 0.000 ) was significantly lower than normative. The association between occupational exposure duration and respiratory symptoms was significant for phlegm production $(p=0.008)$, wheeze $(p=0.008)$, and chest pain $(p=0.01)$. Lung function showed no significant association with exposure duration $\left(p=0.71\right.$ for $\mathrm{FVC}$ and $p=0.45$ for $\left.\mathrm{FEV}_{1}\right)$. Weak negative relationship existed between respiratory symptoms and lung function; phlegm, chest pain, and haemoptysis presented a weak positive relationship.

Conclusions. Respiratory symptoms and impaired lung function are common among foundry workers in Kano State. Exposure duration was a determinant of some respiratory symptoms.

Key words: aluminium, foundry, lung function, respiratory symptoms

\section{Introduction}

Foundry workers are exposed to numerous emissions in their workplaces that are associated with damaging effects on health, such as respiratory diseases from potential inhalation $[1,2]$. This risk is usually a consequence of exposure to different agents like aluminium dust, sulphur dioxide, nitrogen oxides, silica from molten iron, fumes, gases/smokes, and other toxic substances associated with moulding in the foundry industry. Workers are therefore at an increased risk of impaired lung function from chronic exposure to dust and fumes [3, 4]. This is a disturbing trend as suggested by the fact that respiratory symptoms are the most common cause of visiting a general practitioner [5].

Foundry workers primarily deal with various kinds of metals that emit different types of chemicals and gases, which can dangerously impair lung function and predispose to various respiratory conditions [6]. The diseases caused by metallic dust or fumes exposure depend on such factors as the nature of the metal, its physicochemical form, as well as the condition and amount of exposure. Unlike workers of foundries in developed countries, those in developing countries may be at risk of being more exposed to various harmful substances as a result of continuous use of local practices [7, 8]. Moreover, local foundry workers in most developing countries lack adequate protective gears.

In aluminium foundries, the pot room air is composed of dust which mostly contains alumins, aluminium trifluoride, and cryolite, as well as minor amounts of such metals as nickel, chromium, and vanadium [9]. All these elements are potentially harmful to the bronchial tree of the respiratory system. While aluminium is not considered a highly toxic substance, studies have opined that occupational exposure of workers in primary aluminium industry is an important cause of respiratory cancers [10]. Shortness of breath, cough, wheeze, coughing up blood, fever, and chest pain are known symptoms associated with foundry [11].

Health risks related to working in the foundry industry include exposure to molten metal fume (foundry fume), heat and spray mists, and some from dusts produced by casting sand, fettlings, and kiln linings, which contain silica dust, known as respirable crystalline silica [12]. All these are similar to health risk exposure among African foundry workers in Kano State, Nigeria. There are a large number of local aluminium foundry workers there, contributing significantly to the economy of the state. Most of these foundry industries housed all operations within one building, including aluminium melting, pouring of molten aluminium into moulds, shaking out casts from moulds, and grinding of irregularities from casts. All these steps further add to the exposure of foundry workers to emission of dust, gases, and other toxic substances. Despite the health risk of aluminium exposure in individuals whose primary occupation is local foundry, occupation-related health status has not been reported to a large extent among workers in Africa and important respiratory outcomes are likely to be revealed, adding to the fact that most of the workers wear no protective devices at work. To determine whether or not respiratory symptoms are a source of concern

Correspondence address: Aishat Shittu, Department of Physiotherapy, Faculty of Allied Health Sciences, College of Health Sciences, Bayero University, P.M.B 3011, Kano, Nigeria, e-mail: abdulazeezaisha@gmail.com 
among these workers in Kano city, this survey of the workforce was undertaken to describe the prevalence of respiratory symptoms and lung function disorders and to further determine the relationship between the duration of occupation-related exposure and these respiratory outcomes.

\section{Subjects and methods}

This cross-sectional study involved subjects recruited by convenience sampling. The study population comprised only workers of the aluminium foundry located within Kano, Nigeria.

Inclusion criteria:

- being a full-time foundry worker and having signed an informed consent to participate in the study;

- not currently being on medication for a respiratory disease.

Exclusion criteria:

- visible chest deformities and/or self-reported chronic cardio-respiratory disorders.

The sample size for the study was estimated to be 100 foundry workers from Kano city. The sample size estimate was determined by using the following formula:

$$
n=N / 1+N \times E^{2}
$$

where: $n$ - sample size, $N$ - total estimated population $=200$, $E-$ error tolerance $=5 \%$. Thus: $n=200 / 1+200(0.05)^{2}=133$.

\section{Respiratory symptoms assessment}

The American Thoracic Society Division of Lung Diseases (ATS-DLD-78) questionnaire was used to ascertain the prevalence of respiratory symptoms among the participants. This instrument is widely applied in the assessment of respiratory symptoms, and it has been proven to present good psychometric properties and to be a useful adjunct in screening respiratory problems [13].

In this study, questions relevant to the research aims were extracted and administered to the participants. The questions were translated into the Hausa language and back-translated into English. The participants who could not read and write were interviewed instead by research assistants with a good understanding of both English and the local dialects; they used a translated version of the questionnaire.

\section{Lung function assessment}

The participants' lung function was evaluated in accordance with the recommendations of the American Thoracic Society / European Respiratory Society [14] with the aid of a micro-computerized spirometer (a micro plus spirometer MSO4, USA). The procedure was carefully explained to all participants prior to actual measurements. Each subject started the procedure only after it was fully understood. The measurement was performed in a sitting position on a stool. The participants were asked to take the deepest breath possible (total lung capacity), place the mouthpiece (disposable) of the spirometer in their mouth, and in one continuous breath blow via the mouthpiece of the spirometer as hard and as quickly as possible (with maximum effort) till they exhaled the air from their lungs. The procedure was repeated 3 times for each participant to obtain the forced vital capacity (FVC) and forced expiratory volume in the $1^{\text {st }}$ second $\left(F^{\prime} V_{1}\right)$ (in $1 /$ min). The best of the 3 results with less than $5 \%$ variation from another was taken into consideration for analysis.
The recorded values obtained from the foundry workers were compared with the standard predicted normative values for the spirometer (MSO4). Age, sex, and height were used as a basis for comparison to determine the difference in pulmonary function.

\section{Data analysis}

The obtained data were reported by using both descriptive and inferential statistics. The results were summarized as mean, standard deviation, frequency, and percentages. Independent samples $t$-test was applied to compare the lung function of the foundry workers with the normative values. Pearson product-moment correlation served to assess the relationship between the duration of occupation-related exposure and lung function values. Spearman rho correlation coefficient was used to find the relationship between respiratory symptoms and lung function. All analyses were performed with the Statistical Package for the Social Sciences (SPSS) version 16 for Windows. Alpha probability was considered significant at the level of $<0.05$.

\section{Ethical approval}

The research related to human use has complied with all the relevant national regulations and institutional policies, has followed the tenets of the Declaration of Helsinki, and has been approved by the Hospital Management Board, Kano State.

\section{Informed consent}

Informed consent has been obtained from all individuals included in this study.

\section{Results}

The study involved 83 male foundry workers. The age range of the participants was 14-47 (mean: $24.8 \pm 6.7$ ) years. Their average weight, height, and body mass index equalled $55.38 \pm 11.01 \mathrm{~kg}, 1.65 \pm 0.10 \mathrm{~m}$, and $20.2 \pm 2.87\left(\mathrm{~kg} / \mathrm{m}^{2}\right)$, respectively. The results of the study also indicated that $72.3 \%$ (60) of the participants were non-smokers. Out of the 23 participants who reported to be smokers, $73.9 \%$ smoked 1-5 packs per week. The duration of exposure in the study ranged between 2 and 33 years.

The research also revealed that respiratory symptoms were prevalent among the participants. Symptoms such as dyspnoea, cough, wheeze, haemoptysis, and phlegm were recorded. The highest reported respiratory symptom prevalence was for phlegm (69.9\%), followed by cough (33.7\%), while the least reported symptom was haemoptysis (4.8\%), as illustrated in Table 1.

The duration of occupation (in years) varied among the participants. The same referred to the use of protective gears. Overall, $51.8 \%$ of the study subjects had spent 10-19 years in the foundry. Those who had spent less than 10 years accounted for $26.5 \%$. A total of $18.1 \%$ had spent $20-29$ years, while only 3 participants (3.6\%) reported having spent more than 30 years in the foundry industry. A large proportion of the subjects did not use protective gears: $97.6 \%$ and $57.8 \%$ for face mask and hand gloves, respectively (Table 2 ).

Table 3 shows the lung function assessment of the participants against the normative/predicted values. The results indicated that the lung function parameters of the study subjects were significantly lower compared with the normative values $(p \leq 0.05)$. 
Table 1. Respiratory symptoms among the participants

\begin{tabular}{|c|c|c|}
\hline Variable & $n(\%)$ & Prevalence \\
\hline \multicolumn{3}{|c|}{ Dyspnoea } \\
\hline Yes & 13 (15.7) & $15.7 \%$ \\
\hline No & 70 (84.3) & \\
\hline \multicolumn{3}{|l|}{ Cough } \\
\hline Yes & $28(33.7)$ & $33.7 \%$ \\
\hline No & 55 (66.3) & \\
\hline \multicolumn{3}{|c|}{ Haemoptysis } \\
\hline Yes & $4(4.8)$ & $4.8 \%$ \\
\hline No & 79 (95.2) & \\
\hline \multicolumn{3}{|l|}{ Wheeze } \\
\hline Yes & $14(16.9)$ & $16.9 \%$ \\
\hline No & $69(83.1)$ & \\
\hline \multicolumn{3}{|l|}{ Phlegm } \\
\hline Yes & 58 (69.9) & $69.9 \%$ \\
\hline No & $25(30.1)$ & \\
\hline \multicolumn{3}{|c|}{ Chest pain } \\
\hline Yes & $23(27.7)$ & $27.7 \%$ \\
\hline No & $60(72.3)$ & \\
\hline
\end{tabular}

Table 2. Characteristics and occupational exposure of the participants

\begin{tabular}{|l|c|c|}
\hline Variables & $\bar{x} \pm S D$ & $n(\%)$ \\
\hline Age (years) & $24.8 \pm 6.72$ & \\
\hline Height (m) & $1.65 \pm 0.10$ & \\
\hline Weight (kg) & $55.28 \pm 11.01$ & \\
\hline BMl (m/kg $)$ & $20.2 \pm 2.87$ & $43(51.8)$ \\
\hline Occupational exposure & & $15(18.1)$ \\
\hline $10-19$ years & & $3(3.6)$ \\
\hline $20-29$ years & & $2(2.4)$ \\
\hline$\geq 30$ years & & \\
\hline Face mask & & \\
\hline Yes & & \\
\hline No & & \\
\hline
\end{tabular}

BMI - body mass index

Table 3. Lung function comparisons between the study participants and normative values

\begin{tabular}{|c|c|c|c|c|}
\hline Variable & $n$ & $\bar{x} \pm S D$ & $t$ & $p$ \\
\hline Mean FVC (study participants) & 83 & $2.761 \pm 0.77$ & \multirow{2}{*}{-16.67} & \multirow{2}{*}{$0.000^{*}$} \\
\hline Mean FVC (normative data) & 83 & $4.317 \pm 0.65$ & & \\
\hline 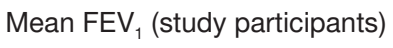 & 83 & $2.349 \pm 0.69$ & \multirow{2}{*}{-17.43} & \multirow{2}{*}{$0.000^{*}$} \\
\hline Mean FEV 1 (normative data) & 83 & $3.659 \pm 0.52$ & & \\
\hline
\end{tabular}

$\mathrm{FEV}_{1}$ - forced expiratory volume in $1^{\text {st }}$ second, FVC - forced vital capacity, $t-t$-test critical value, $S D$ - standard deviation

* significant at 0.05 alpha level
A weak negative relationship was found between the reported respiratory symptoms and the lung function. Only phlegm production and chest pain demonstrated a weak positive relationship with FVC, while haemoptysis, phlegm production, and chest pain showed a weak positive correlation with $\mathrm{FEV}_{1}$ (Table 4).

Table 4. Relationship between lung function and respiratory symptoms

\begin{tabular}{|c|c|c|}
\hline Variables & $r$ & $p$ \\
\hline \multicolumn{3}{|l|}{ FVC (I/min) } \\
\hline Dyspnoea & -0.024 & 0.832 \\
\hline Cough & -0.063 & 0.573 \\
\hline Haemoptysis & -0.259 & $0.018^{*}$ \\
\hline Wheeze & -0.015 & 0.890 \\
\hline Phlegm & 0.089 & 0.422 \\
\hline Chest pain & 0.026 & 0.812 \\
\hline \multicolumn{3}{|l|}{$\mathrm{FEV}_{1}(1 / \mathrm{min})$} \\
\hline Dyspnoea & -0.077 & 0.491 \\
\hline Cough & -1.121 & 0.277 \\
\hline Haemoptysis & 0.163 & 0.140 \\
\hline Wheeze & -0.076 & 0.493 \\
\hline Phlegm & 0.030 & 0.788 \\
\hline Chest pain & 0.101 & 0.363 \\
\hline
\end{tabular}

$\mathrm{FEV}_{1}$ - forced expiratory volume in $1^{\text {st }}$ second,

FVC - forced vital capacity, $r$ - relationship

* significant at $p<0.05$

Table 5 presents the association between occupational exposure duration (in years) and the respiratory symptoms and lung function. A significant association existed for phlegm production $(p=0.008)$, wheeze $(p=0.008)$, and chest pain $(p=0.01)$. Lung function variables showed no significant association with exposure duration (FVC: $p=0.71$; $\mathrm{FEV}_{1}$ : $p=0.45)$.

\section{Discussion}

The presented study assessed the prevalence of respiratory symptoms and evaluated lung function among aluminium foundry workers in Kano State. This is the first attempt to report on this important public health issue. All the participants were males aged 14-47 years, implying that foundry is an occupation dominated by males in the most productive age range. This study also assessed the smoking habit among the participants. It was to rule out bias and increase the reliability of our findings since cigarette smoking is widely known to be associated with poor lung condition, as well as respiratory symptoms $[15,16]$. The smoking habit profile of the study subjects was generally favourable; hence, the respiratory outcomes can be reliably attributed to foundry practices.

The study revealed that phlegm production, as well as persistent coughing chest pain, wheeze, and dyspnoea were common respiratory symptoms among the participants. This is not surprising as their attitude to the use of protective gears was generally poor and the production environment was not well ventilated. More importantly, these findings corroborate earlier studies among male foundry workers in Taiwan [2] and 
Table 5. Association between respiratory symptoms, lung function, and work duration

\begin{tabular}{|c|c|c|c|c|c|c|}
\hline Variables & $1-9$ years & $10-19$ years & $20-29$ years & Above 30 years & $\mathrm{X}^{2} /$ Fisher & $p$ \\
\hline $\begin{array}{l}\text { Phlegm } \\
\text { Yes } \\
\text { No }\end{array}$ & $\begin{array}{l}11 \\
11\end{array}$ & $\begin{array}{l}31 \\
12\end{array}$ & $\begin{array}{r}13 \\
2\end{array}$ & $\begin{array}{l}3 \\
0\end{array}$ & 6.64 & $0.008^{\star}$ \\
\hline $\begin{array}{l}\text { Wheeze } \\
\text { Yes } \\
\text { No }\end{array}$ & $\begin{array}{r}0 \\
22\end{array}$ & $\begin{array}{r}8 \\
35\end{array}$ & $\begin{array}{r}3 \\
12\end{array}$ & $\begin{array}{l}3 \\
0\end{array}$ & 6.64 & $0.008^{\star}$ \\
\hline $\begin{array}{l}\text { Chest pain } \\
\text { Yes } \\
\text { No }\end{array}$ & $\begin{array}{r}3 \\
19\end{array}$ & $\begin{array}{l}12 \\
31\end{array}$ & $\begin{array}{r}5 \\
10\end{array}$ & $\begin{array}{l}3 \\
0\end{array}$ & 8.79 & $0.010^{*}$ \\
\hline \begin{tabular}{|l} 
Dyspnoea \\
Yes \\
No
\end{tabular} & $\begin{array}{r}0 \\
22\end{array}$ & $\begin{array}{l}10 \\
33\end{array}$ & $\begin{array}{r}3 \\
12\end{array}$ & $\begin{array}{l}0 \\
3\end{array}$ & 7.13 & 0.217 \\
\hline $\begin{array}{l}\text { Haemoptysis } \\
\text { Yes } \\
\text { No }\end{array}$ & $\begin{array}{r}1 \\
21\end{array}$ & $\begin{array}{r}3 \\
40\end{array}$ & $\begin{array}{l}0 \\
5\end{array}$ & $\begin{array}{l}0 \\
3\end{array}$ & 1.32 & 0.528 \\
\hline $\begin{array}{l}\text { Cough } \\
\text { Yes } \\
\text { No }\end{array}$ & $\begin{array}{r}7 \\
15\end{array}$ & $\begin{array}{l}13 \\
30\end{array}$ & $\begin{array}{r}5 \\
10\end{array}$ & $\begin{array}{l}3 \\
0\end{array}$ & 5.34 & 0.193 \\
\hline FVC & 22 & 43 & 15 & 3 & 241.78 & 0.707 \\
\hline $\mathrm{FEV}_{1}$ & 22 & 43 & 15 & 3 & 266.80 & 0.448 \\
\hline
\end{tabular}

* significant at $p<0.05$

among iron and steel foundry workers in Canada [11] and Turkey [17]. The fact that this has been long reported underscores the need for effective strategies aimed at modifying the foundry industry in developing countries.

Another important result of our study was the significant lowering of the participants' lung function values compared with the normative data. Even though we could not draw more inference from these results in terms of ascertaining whether they may have contributed to any obstructive or restrictive respiratory condition, the findings corroborate an earlier study [18]. The results remain relevant as they highlight a possible pattern that may be of prognostic value. Additionally, since no correlation was observed between the duration of occupation-related exposure and lung function values, the results are only suggestive of a possible negative impact of foundry occupation generally.

We also revealed that wheeze, phlegm, and chest pain were significantly correlated with the occupational-related exposure. This finding is supported by a study which reported that chronic respiratory symptoms are majorly a consequence of exposure to air pollutant s among foundry workers. It is also plausible that other factors that predispose individuals to persistent infections (bronchitis) over time, such as inhalation of various substances, fumes, and vapours play a larger role $[18,19]$.

The investigated lung function parameters showed a weak negative correlation, though insignificant, with the duration of occupation-related exposures. This is in agreement with the results of studies that consistently linked long-term exposure to dust and fumes from aluminium-related activities with signs of decreased lung function [20]. Also, it is only logical to attribute the reduction in $\mathrm{FEV}_{1}$ and $\mathrm{FVC}$ values to long-term exposure to harmful elements, such as gases and fumes, in the foundry industries [21]. Nonetheless, the weak negative relationship of the study results may be due to the relatively small sample size and partly to the fact that the majority of our study participants had less than 20 years
The relationship between the reported respiratory symptoms and lung function, although negative and weak in this study (which can partly be attributed to the number of working years, which was less than 20), is a cause for concern as there is a tendency that the continuous presence of respiratory symptoms in these workers can further have a detrimental effect on the lung function over a longer period of exposure.

The study highlights the need for a change in the attitude among foundry workers in cities of developing countries where local foundry is practised. A large-scale epidemiological survey is also required. For the time being, adequate public enlightenment campaigns can be commissioned with a view to educating foundry workers on the need to utilize protective gears such as face masks, gloves, and uniforms while at work.

\section{Acknowledgements}

The authors thank the Ministry of Health in Nigeria for granting us permission to conduct the study and appreciate the foundry workers for their maximum cooperation received during the course of this work.

\section{Disclosure statement}

No author has any financial interest or received any financial benefit from this research.

\section{Conflict of interest}

The authors state no conflict of interest.

\section{References}

1. Rybina T, Kardash V, Semizhon S, Zaitsev V, Rybina A, Kardash $\mathrm{H}$. Lung function and element status of foundry workers. Eur Respir J. 2016;48:PA4284; doi: 10.1183/ 13993003.congress-2016.PA4284.

2. Kuo H-W, Chang C-L, Liang W-M, Chung B-C. Respiratory abnormalities among male foundry workers in central Taiwan. Occup Med. 1999;49(8):499-505; doi: 10.1093/occmed/49.8.499. 
3. Gomes J, Lloyd OL, Norman NJ, Pahwa P. Dust exposure and impairment of lung function at a small iron foundry in a rapidly developing country. Occup Environ Med. 2001;58(10):656-662; doi: 10.1136/oem.58.10.656.

4. Abedghars MT, Hadji A, Bouhouch S. Monitoring of air quality in an iron foundry (case of $\mathrm{NOx}, \mathrm{SO}_{2}$, benzene and dust). J Mater Environ Sci. 2011;2(S1):501-506.

5. Vaidya P, Kashyap S, Sharma A, Gupta D, Mohapatra PR. Respiratory symptoms and pulmonary function tests in school teachers of Shimla. Lung India. 2007;24(1):6-10; doi: 10.4103/0970-2113.44195.

6. Søyseth V, Kongerud J. Prevalence of respiratory disorders among aluminium potroom workers in relation to exposure to fluoride. Br J Ind Med. 1992;49(2):125-130; doi: 10.1136/oem.49.2.125.

7. Becklake MR. Occupational exposures: evidence for a causal association with chronic obstructive pulmonary disease. Am Rev Respir Dis. 1989;140(3 Pt 2):S85-S91; doi: 10.1164/ajrccm/140.3_Pt_2.S85.

8. Oxman AD, Muir DC, Shannon HS, Stock SR, Hnizdo E, Lange HJ. Occupational dust exposure and chronic obstructive pulmonary disease. A systematic overview of the evidence. Am Rev Respir Dis. 1993;148(1):38-48; doi: 10.1164/ajrccm/148.1.38.

9. O'Donnell TV, Welford B, Coleman ED. Potroom asthma: New Zealand experience and follow-up. Am J Ind Med. 1989;15(1):43-49; doi: 10.1002/ajim.4700150106.

10. Rönneberg A, Langmark F. Epidemiologic evidence of cancer in aluminum reduction plant workers. Am J Ind Med. 1992;22(4):573-590; doi: 10.1002/ajim.4700220412.

11. Johnson A, Moira CY, MacLean L, Atkins E, Dybuncio A, Cheng $F$, et al. Respiratory abnormalities among workers in an iron and steel foundry. Br J Ind Med. 1985;42(2):94100; doi: 10.1136/oem.42.2.94.

12. Mgonja CT. A review on effects of hazards in foundries to workers and environment. Int J Innov Sci Eng Technol. 2017;4(6):326-334; doi: 10.13140/RG.2.2.24642.27847.

13. Price DB, Tinkelman DG, Halbert RJ, Nordyke RJ, Isonaka S, Nonikov D, et al. Symptom-based questionnaire for identifying COPD in smokers. Respiration. 2006;73(3): 285-295; doi: 10.1159/000090142.

14. Batmaz SB, Arıkoğlu T, Tamer L, Eskandari G, Kuyucu S. Seasonal variation of asthma control, lung function tests and allergic inflammation in relation to vitamin D levels: a prospective annual study. Adv Dermatol Allergol. 2018; 35(1):99-105; doi: 10.5114/ada.2017.71421.

15. Menzies D, Nair A, Williamson PA, Schembri S, Al-Khairalla $\mathrm{MZH}$, Barnes $\mathrm{M}$, et al. Respiratory symptoms, pulmonary function, and markers of inflammation among bar workers before and after a legislative ban on smoking in public places. JAMA. 2006;296(14):1742-1748; doi: 10.1001/jama.296.14.1742.

16. Willemse BWM, Postma DS, Timens W, ten Hacken NHT. The impact of smoking cessation on respiratory symptoms, lung function, airway hyperresponsiveness and inflammation. Eur Respir J. 2004;23(3):464-476; doi: 10.1183/09031936.04.00012704.

17. Kayhan S, Tutar U, Cinarka H, Gumus A, Koksal N. Prevalence of occupational asthma and respiratory symptoms in foundry workers. BMC Pulm Med. 2013;370138; doi: $10.1155 / 2013 / 370138$.

18. Aminian O, Reza Mozafari SA, Haghighi KS, Chavoshi F, Saraie M, Izadi N. Study of respiratory symptoms and pulmonary function in cotton textile workers. J Basic Appl Sci Res. 2013;3(4):33-36.
19. McLaughlin AIG, Kazantzis G, King E, Teare D, Porter RJ, Owen R. Pulmonary fibrosis and encephalopathy associated with the inhalation of aluminium dust. $\mathrm{Br} \mathrm{J}$ Ind Med. 1962;19(4):253-263; doi: 10.1136/oem.19.4.253.

20. Zeleke ZK, Moen BE, Bråtveit M. Cement dust exposure and acute lung function: a cross shift study. BMC Pulm Med. 2010;10:19; doi: 10.1186/1471-2466-10-19.

21. Xu X, Christiani DC, Dockery DW, Wang L. Exposureresponse relationships between occupational exposures and chronic respiratory illness: a community-based study. Am Rev Respir Dis. 1992;146(2):413-418; doi: 10.1164/ ajrccm/146.2.413. 